\title{
Relações entre os estudos sobre deficiência e os Estudos das Ciências, Tecnologias e Sociedades: a acessibilidade como forma de tradução
}

Relationships between Disability Studies and Science, Technology and Society Studies: accessibility as a form of translation

Carla Grião

Universidade de São Paulo - Brasil

São Paulo, Brasil

carlagriao@usp.br

Cláudio Bernardino Junior

Universidade de São Paulo - Brasil

São Paulo, Brasil

claudiobjr@usp.br

\section{RESUMO}

O presente artigo busca compreender a ideia de acessibilidade, amplamente discutido pelos estudos sobre deficiências, a partir do conceito de tradução utilizado pelos Science, Technology and Society studies (STS studies). Para isso, parte-se da experiência do Movimento Social das Pessoas com Deficiência na Cidade de São Paulo, cujo a atuação foi retratada a partir de peças publicadas na imprensa paulistana entre os anos de 1978 e 1981, além de referências bibliográficas especializadas. Segue-se apresentando os conceitos teóricos dos STS studies considerados mais relevantes para a compreensão do objeto de estudo, partindo-se, em seguida, para a exploração das intersecções entre acessibilidade e tradução. Conclui-se que através da escolha de traduções democráticas e mais adequada ao padrão real, que é a diversidade, é possível construir uma sociedade mais igualitária e inclusiva sem a necessidade de acréscimos que resultam apenas de adaptações razoáveis.

Palavras chaves: Pessoas com Deficiência; Acessibilidade; STS studies; Tradução.

\section{ABSTRACT}

This paper seeks to understand the idea of accessibility, widely discussed by disability studies, from the concept of translation used by STS Studies. To this end, it starts from the experience of the Social Movement of People with Disabilities in the city of São Paulo, whose actions were portrayed based on pieces published in the São Paulo press between the years 1978 and 1981, in addition to specialized bibliographical references. The theoretical concepts of the STS studies considered most relevant to the understanding of the object of study are then presented, followed by an exploration of the intersections between accessibility and translation. It is concluded that through the choice of democratic translations that are more appropriate to the real pattern, which is diversity, it is possible to build a more egalitarian and inclusive society without the need for additions that result only from reasonable adaptations.

Keywords: Disabled Persons; Accessibility; STS studies; Translation 


\section{INTRODUÇÃO}

A história dos movimentos sociais das pessoas com deficiência é uma história pouco contada no Brasil. Abundam bibliografias sobre o movimento negro, o movimento feminista, o movimento LGBTQIA+ etc., mas o movimento das pessoas com deficiência é quase um movimento invisível. Em São Paulo, ele ganha força no final dos 1970 e início dos anos 1980, reivindicando melhores condições de circulação pela cidade, passando por melhores oportunidades de empregos, estudos, saúde, enfim, buscando o básico para uma existência com dignidade. Ou seja, há pouco mais de quarenta anos, pessoas com deficiência reivindicam uma sociedade acessível.

O presente artigo parte dessa luta, explorando a sociedade paulistana do período e chamando atenção para algumas pautas do movimento. A partir da história do Movimento Social das Pessoas com Deficiência em São Paulo, propomos uma leitura do próprio conceito de acessibilidade baseada nos estudos da deficiência e nos estudos das ciências, tecnologias e sociedade, os chamados STS studies (Science, Technology and Society studies).

Até o momento, observamos que essas duas vertentes de estudo possuem poucas intersecções no Brasil. Em poucas palavras, podemos definir os estudos da deficiência como aqueles que buscam compreender, historicamente, as maneiras de inserção das pessoas com deficiência nas sociedades. Já os estudos sobre ciências, tecnologia e sociedade, são pesquisas cuja principal característica é acabar com as categorias apriorísticas da natureza (tudo que não é humano) e sociedade (tudo o que é humano).

Frisamos essa distinção. De acordo com Bruno Latour (2009), a epistemologia kantiana que segrega seres humanos de todos os outros seres e coisas ditas inanimadas que compõe o mundo perdeu a sua força a partir de 1989 com a emergência da natureza. A partir daí, não é mais possível imaginar uma sociedade apartada da natureza, cujo desenvolvimento é livre e limitado apenas pelo engenho das pessoas. Bruno Latour argumenta firmemente e em todas as suas obras que natureza e sociedade não podem ser separadas de antemão, uma vez que ambas simplesmente fazem parte do lugar que todos habitamos. Esse lugar-comum é chamado por Latour de coletivo. Em um coletivo, estão associados humanos e não-humanos, interconectados e existindo de maneira codependente. Essa é a primeira ideia que salientamos como uma importante intersecção entre STS studies e os estudos da deficiência: biológico e social não podem ser compreendidos como independentes, pois um influencia diretamente no outro.

Essa interdependência está, de certa forma, presente nos atuais estudos acerca da deficiência, como, por exemplo, nas publicações de Débora Diniz, autora brasileira que é referência nesta área. Em seu livro O que é deficiência? (Diniz, 2012) Diniz discute conceitos como barreiras, acessibilidade e, obviamente, deficiência.

Aparentemente, esse conceito pode parecer simples, objetivo e autoexplicativo. Contudo, a autora mostra que a compreensão do que é deficiência é histórica e possui majoritariamente três modelos explicativos: o modelo caritativo, o modelo médico (ou biomédico) e o modelo social, atualmente o mais utilizado em estudos da área. De maneira resumida, o primeiro é baseado na ideia de que a pessoa com deficiência é vítima de uma vida repleta de sofrimentos e, portanto, precisa de ajuda, de caridade daqueles que não passaram pelas mesmas provações que as pessoas com deficiência passam; o segundo compreende a deficiência como um mau desenvolvimento do corpo, visto através de uma ideia de normalidade biológica; o terceiro defende que a deficiência é uma relação complexa entre um corpo com lesão e uma sociedade excludente caracterizada pela existência de barreiras. A acessibilidade aparece aqui como uma forma de eliminação dessas barreiras, possibilitando assim que a pessoa com deficiência frua dos espaços e da vida social da mesma forma que as demais. 
A acessibilidade é popularmente vista como uma espécie de "contorno" às barreiras, contorno este que possibilita que a pessoa com deficiência utilize tenha acesso a direitos sociais. Consideramos esse a segunda intersecção entre STS studies e deficiência: existe um "elemento" que faz com que pessoas com deficiência se "associem" a um coletivo que não foi pensado para elas. Utilizando o referencial teórico dos estudos das ciências, tecnologias e sociedades, chamaremos esse elemento de tradução.

Esse artigo defende que toda forma de acessibilidade é uma forma de tradução. Consideramos que essa é a principal e a mais importante contribuição que esboçamos para as duas áreas de estudo. Nos STS studies, a tradução é inerente a qualquer forma de associação, ou seja, não existe coletivo sem traduções. Traduções existem em abundância e ajudam a nos conectarmos uns aos outros e aos espaços em que vivemos.

Aqui identificamos o ponto que acreditamos ser o que distancia os STS studies e estudos sobre deficiência: para o segundo, a acessibilidade é compreendida como recursos ou atitudes diferentes daquelas difundidas e que existem para atender a pessoas com deficiência ou a indivíduos que escapam do padrão socialmente instituído de ser humano (idosos, mulheres grávidas, crianças etc.). Para o primeiro, as traduções são recursos e atitudes essenciais para a existência de todos. Encarar a acessibilidade como tradução nos permite deslocar a atenção do "acréscimo" de recursos para a seleção dos recursos. A partir daí, levantamos a questão: por que socialmente escolhemos algumas traduções no lugar de outras?

Acreditamos, ainda, que compreender que traduções são inerentes ao coletivo permite dar um passo para trás em relação aos questionamentos feitos pela ideia de acessibilidade e indagar, por exemplo, não a inexistência de rampas, mas a existência de escadas.

O desenvolvimento desse artigo foi pensado em três partes. Na primeira, apresentaremos a história do Movimento Social da Pessoa com Deficiência na Cidade de São Paulo entre os anos de 1978 a 1981. A seção é baseada na dissertação de mestrado de Carla Grião, ainda a ser defendida. Na segunda, aprofundamos o conceito de tradução baseado nas análises dos STS studies. E nas discussões publicadas na dissertação de mestrado de Cláudio Bernardino Junior (2020). Defendemos que as escolhas feitas por determinadas traduções são frutos direto de uma visão padronizada de ser no mundo. Na terceira parte, aproximaremos com mais detalhes os conceitos de tradução e de acessibilidade.

\section{METODOLOGIA}

Utilizamos a análise bibliográfica e a pesquisa de periódicos disponíveis em acervos históricos na internet. Foram utilizados, sobretudo, as peças publicadas pelo jornal Folha de São Paulo entre 1978 e 1981. A tabela com os dados quantitativos que embasam as afirmações das transformações sociais ocorridas em São Paulo no tocante à pessoa com deficiência encontrar-se-ão disponíveis na dissertação de metrado intitulada Lugares de Memória do Movimento Social das Pessoas com Deficiência na cidade de São Paulo de 1978 a 1981. Sobre a bibliografia, cabe ressaltar que as publicações a respeito da história do Movimento Social das Pessoas com Deficiência em São Paulo são escassas e, as existentes, são majoritariamente pautadas sobretudo na reprodução de depoimentos dados pelos militantes aos autores. Por esta razão, sentimos a necessidade de cruzar esses relatos com os publicados pela imprensa no período, buscando assim criar uma narrativa coerente a respeito do contexto histórico da cidade de São Paulo e da atuação do Movimento. 


\section{DESENVOLVIMENTO}

\subsection{A cidade de São Paulo para as pessoas com deficiência entre 1978 e 1981}

Não é possível compreender a importância da intersecção das ideias de acessibilidade e tradução sem compreendermos como pessoas com deficiência vivem em uma cidade não acessível. As poucas rampas, elevadores e guias rebaixadas nas calçadas da cidade de São Paulo foram frutos de uma luta quase invisível empreendida por pessoas com deficiência desde o final dos anos 1970.

Nessa seção, traçaremos um panorama da cidade de São Paulo e das dificuldades enfrentadas pelas pessoas com deficiência. A evidente exclusão que vivenciavam os levou à mobilização e à reivindicação de seus direitos.

Como definiu a jornalista Cecília Pires no Jornal Folha de São Paulo (Pires, 1981), São Paulo era "uma cidade proibida para o deficiente físico". Essa conclusão foi formulada após a participação da autora em seminários, encontros, debates e conferências organizados principalmente pelo Movimento pelos Direitos das Pessoas Deficientes (MDPD) para a organização do Ano Internacional da Pessoa Deficiente (AIPD) no Brasil. O AIPD foi uma iniciativa da Organização das Nações Unidas (ONU) para chamar atenção dos poderes púbicos de todos os países signatários para as demandas das pessoas com deficiência.

O período de 1978 a 1981 foi um período de transformação na imagem que esse público possuía diante da sociedade paulistana. Análises quantitativas das matérias publicadas no jornal Folha de São Paulo mostram que, até 1980, as pessoas com deficiência apareciam na imprensa paulistana, sobretudo em matérias relacionadas ao comércio ambulante no centro da cidade. Até então, o jornal lhes dava pouca voz. Na maior parte das vezes em que pessoas com deficiência eram ouvidas, elas faziam acusações de corrupção contra o então presidente da Associação Brasileira dos Deficientes Físicos (Abradef), como pode ser observado em, por exemplo, “Os ambulantes estão contra novas bancas", 1979. Nestas matérias, eram os comerciantes locais aqueles que possuíam o discurso reproduzido com mais ênfase, normalmente afirmando que o comércio ambulante levava sujeira, intranquilidade e crimes para os transeuntes (Editorial, 9 de maio de 1980, p. 5). Observamos, portanto, um certo incômodo social em relação às pessoas com deficiência.

A permissão para ocupar o centro de São Paulo como ambulantes era uma das poucas políticas que buscavam integrar economicamente a pessoa com deficiência à sociedade. Mesmo existindo uma legislação em São Paulo que obrigava a contratação de 5\% de pessoas com deficiência para a composição do quadro de funcionários de algumas empresas, tratava-se, na prática, de letra morta, levando por vezes a manifestações que exigiam o seu cumprimento (Editorial, 22 de julho de 1980, p. 11).

Essa inserção periférica da pessoa com deficiência no mercado de trabalho trazia consequências até para o acesso do grupo à saúde pública, prejudicando os tratamentos que eventualmente estariam disponíveis. Como não existia um sistema universal de saúde, o extinto Instituto Nacional de Assistência Médica da Previdência Social (INAMPS) fornecia atendimento médico à população. Por estar vinculado à previdência social, o INAMPS estava disponível apenas para os trabalhadores que contribuíam para o serviço, ou seja, apenas para aqueles que possuíam um trabalho formal, o que excluía uma parcela considerável da população, incluindo diversas pessoas com deficiência. Desempregados e trabalhadores informais dependiam sobretudo dos hospitais universitários e dos centros de caridade (Escola Politécnica de Saúde Joaquim Venâncio, [s.d.]). 
O acesso à educação também era dificultado. Como as crianças com deficiência eram segregadas das demais, faltavam salas ou escolas especiais. Além disso, crianças surdas, para se matricularem no ensino regular, precisaram possuir aparelhos auditivos cujos preços variavam de $\mathrm{Cr} \$ 5.000,00$ a $\mathrm{Cr} \$ 10.000,00$ (entre $\mathrm{R} \$ 879,16$ e $\mathrm{R} \$ 1.758,32 \mathrm{em}$ valores atualizados para 2021). O INAMPS, entre 1976 e 1978, chegou a distribuir 311 aparelhos do tipo, um número claramente insignificante. Para agravar a situação, encontramos relatos de pais que se recusavam a matricular os filhos em salas especiais porque essas turmas eram frequentadas por crianças com deficiência intelectual ou comunicacional (Editorial, 30 de abril de 1974, p. 10).

Em relação à locomoção das pessoas com deficiência pela cidade, a situação também era precária. Até 1981, a cidade de São Paulo possuía cinco rotas que pensavam na circulação de pessoas ou em cadeira de rodas ou com deficiência visual. Chamamos especial atenção para a localização dessas rotas: uma ao redor do Parque do Ibirapuera, ligando-o ao Lar Escola São Francisco, no Jardim Lusitânia; uma nas proximidades da Fundação para o Livro do Cego no Brasil, ligando a instituição à Estação Santa Cruz do Metrô; uma nas imediações da Abradef, ligando-a à Estação Ana Rosa do Metrô; uma para "eliminar as barreiras do interior do Centro Educacional e Esportivo do Ibirapuera"; e, finalmente, uma que ligaria a Estação Vergueiro do Metrô à Divisão de Recuperação Profissional do Vergueiro, vinculada ao Hospital das Clínicas (Editorial, 11 de maio de 1980, p. 21).

Todas as instituições acima citadas prestavam serviços básicos a pessoas com deficiência, ou seja, as rotas planejadas pela prefeitura de São Paulo serviam quase que exclusivamente para ligar o transporte público metroviário a espaços de assistência, seja à saúde ou à educação, demonstrando que, para o poder público, possibilitar a subsistência da pessoa com deficiência já era o suficiente. Aos demais cidadãos, contudo, estavam disponíveis toda uma gama de benefícios: dos básicos, como circular pelas calçadas sem colocar a saúde em risco, até espaços de lazer mais complexos, como parques, teatros, cinemas, praças etc.

O direcionamento das pessoas com deficiência para determinados espaços fica muito claro, também, na criação da linha de ônibus Vila Mariana - Jardim Lusitânia, uma linha exclusiva dedicada a este público. Em seus $11 \mathrm{~km}$ de extensão, os ônibus atendiam "quase todos os centros de reabilitação de deficientes físicos da cidade". A linha era composta por dois carros comuns que circulavam em intervalos de 15 minutos e contavam com motoristas e cobradores treinados para o atendimento de pessoas com deficiência. Em maio, durante a inauguração do percurso, a prefeitura informou que a adaptação dos veículos se daria em três meses, com o rebaixamento dos degraus e facilidades de acesso e saída dos passageiros (Editorial, 1 de maio de 1981, p. 9). Ou seja, curiosamente a linha exclusiva para pessoas com deficiência demorou três meses para possuir carros adaptados para as pessoas com deficiência. Não por acaso, no dia seguinte do anúncio da inauguração da linha, o jornal Folha de São Paulo afirmava: "ônibus especial não atende deficientes”. Existiam vários problemas com os carros: as portas não eram largas o suficiente, as escadas deveriam ser substituídas por rampas, os bancos deveriam ser redimensionados e as catracas retiradas (Editorial, 1 de maio de 1981, p. 9). Apenas em junho de 1981, a Companhia Municipal de Transportes Coletivos (CMTC) anunciou que colocaria ônibus com elevadores na porta para atender ao público com deficiência.

Com algumas exceções, as (poucas) políticas públicas disponíveis para as pessoas com deficiência eram falhas, talvez porque, como denunciava o MDPD, não contavam com a participação de pessoas com deficiência na sua elaboração. Um exemplo é a Comissão Federal criada pelo presidente João Baptista Figueiredo (1979 - 1985) em 1980 e que seria responsável pela implementação das medidas para o AIPD no Brasil. A Comissão, cuja presidência foi entregue para a professora Helena Bandeira de Figueiredo, seria composta por dois representantes do 
Ministério da Educação e Cultura, dois do Ministério da Previdência e Assistência Social, um do Ministério da Saúde, um do Ministério do Trabalho, um do Ministério das Relações Exteriores, um da Secretaria de Planejamento, um da Secretaria de Comunicação Social, um de entidade não governamental de reabilitação e educação de pessoas com deficiência e um representante de entidades não governamentais interessadas na prevenção de acidentes no trabalho, no trânsito e domésticos (Decreto $n^{\circ} 85.123$, de 10 de Setembro de 1980, 1980). Além de, inicialmente, não possuir nenhuma pessoa com deficiência, para Luís Celso Marcondes de Moura, Coordenador Geral do MDPD, a Comissão Federal sequer escutava o que as pessoas com deficiência teriam para dizer (Ortiz, 1981).

A própria construção das rotas de acessibilidade a qual nos referimos anteriormente foi realizada sem que nenhuma pessoa com deficiência fosse consultada. As dificuldades em se locomover pela cidade em uma cadeira de rodas fora vivenciada por um grupo de engenheiros e arquitetos sem deficiência que trabalhava na Companhia de Engenharia de Tráfego (CET) que, utilizando uma cadeira de rodas talvez pela primeira, percorreu diversas vezes os caminhos analisados para assim verificar as barreiras existentes (Editorial, 11 de maio de 1980).

Diante deste cenário, grupos de pessoas com deficiência se mobilizaram e buscaram promover ações para assim garantir acesso a direitos humanos básicos. Esses grupos compõem o que chamamos genericamente de Movimento Social das Pessoas com Deficiência. O já referido MDPD organizou em 1981 diversas mesas redondas realizadas no Colégio Anchietanum, em Sumaré. Em abril, discutiu-se o espaço urbano; em maio, o trabalho; em junho, transportes; julho, assistência médica, reabilitação e equipamentos auxiliares; agosto, legislação; setembro, lazer e esportes; outubro, educação; e novembro, relações humanas e sociais (Editorial, 13 de março de 1981). Muitos desses encontros contaram com a participação de autoridades públicas.

Outro exemplo de atuação de entidades do Movimento Social foi a organização da "Feira das Feiras" pelo Núcleo de Integração de Deficientes (NID). A proposta era propiciar ao público em geral uma vivência com barreiras para assim refletirem sobre a importância na existência de espaços acessíveis. De acordo com Silva,

Foram construídos caminhos com degraus e desníveis, havia várias cadeiras de rodas para as pessoas experimentarem a dificuldade de estar em uma cadeira de rodas diante de degraus. Assim como outras dificuldades que as pessoas com deficiência encontram no seu dia a dia, como: altura de orelhão, a altura da pia, do espelho: "tudo tinha amostra do errado e do certo" (Silva, 2017, p. 100-101).

Além de organizar debates e vivências buscando a conscientização da população em geral, as entidades ligadas ao Movimento Social organizaram manifestações de rua para reivindicarem seus direitos. Em carta enviada à seção "A Palavra do Leitor”, do jornal Folha de São Paulo, Lia Crespo, militante do NID, afirmou:

A única forma de nos fazer ouvir é nos tornarmos notícia. Talvez assim possamos mostrar que nossa briga pela sobrevivência não é tão difícil quanto parece. Na verdade, é muito mais difícil do que parece. Só que não estamos inteiramente perdidos porque conseguimos manter viva nossa capacidade de rir de nós mesmos. (...) Ainda é uma ideia em embrião, mas temos fé em que nosso pequeno grupo se torne uma verdadeira associação para trocas de experiência e ajuda mútua; além de, naturalmente, lutar para que sejam tomadas as providências e medidas que julgamos ser do nosso direito conquistar (Editorial, 19 de março de 1980, p. 31). 
Um bom exemplo da proposta de "tornar-se notícia” foi a manifestação ocorrida em 21 de julho de 1980 na Praça da Sé. Nesse momento, foram reunidas duzentas pessoas com deficiência portando faixas e cartazes e protestando contra a "perseguição dos fiscais da Prefeitura aos vendedores ambulantes". Como a situação da pessoa com deficiência era precária, a pauta estava muito além da questão dos ambulantes: exigia-se o cumprimento da legislação que garantia os direitos humanos ao grupo, como a lei que exigia a contratação de $5 \%$ de pessoas com deficiência do total de trabalhadores de uma empresa; o cumprimento da lei que regulamentava o trabalho de vendedor de bilhetes de loteria (como as lotéricas monopolizavam as vendas, as pessoas com deficiência precisavam comprar os bilhetes do "câmbio negro"); exigia-se degraus mais baixos nos ônibus, bem como a instalação de rampas automáticas nos mesmos para acesso de cadeira de rodas; até a situação dos táxis entraram nas reivindicações: pedia-se a abolição dos bancos dianteiros para facilitar o transporte da cadeira de rodas. Por fim, chamavam atenção para o estado de conservação das calçadas e o tempo muito curto que os semáforos de pedestres davam aos indivíduos para atravessarem as ruas (Editorial, 22 de julho de 1980, p. 11).

Romeu Sassaki, um importante assistente social muito atuante no Movimento Social das Pessoas com Deficiência, falou no livro Movimento Político das Pessoas com Deficiência no Brasil (Lanna Júnior, 2010) a respeito de outra manifestação, desta vez ocorrida em 17 de julho de 1981, em frente ao Theatro Municipal por conta da falta de rampas de acesso para pessoas em cadeira de rodas usufruírem da programação. Nesta ocasião, os manifestantes carregavam cartazes com frases como: “Não somos coitadinhos, queremos ser úteis", "Quem nos defende?", "Podemos não ser perfeitos, mas há partes de nós que são maravilhosas.", "Queremos rampas nos lugares públicos.", "Nos dê oportunidade de trabalho", entre outras.

A manifestação narrada por Sassaki é um exemplo de sublevação das pessoas com deficiência frente ao papel que lhe era atribuída no coletivo paulistano. A prefeitura "permitia", através das rotas acessíveis, que o grupo procurasse atendimento médico, assistência para reabilitação e centros de educação especializado. O restante da cidade, por não possuir recursos acessíveis, Ihes era, na prática, negado. Contudo, pessoas com deficiência queriam o direito de frequentar o teatro e ter, assim, algum tipo de lazer. As manifestações aumentavam a "força” que o grupo possuía, uma vez que agenciava diversos indivíduos, seja diretamente através da manifestação, seja indiretamente através dos veículos de comunicação que, ao noticiarem o evento, certamente indignavam alguns cidadãos sem deficiência. Não por acaso, pouco tempo depois, rampas foram instaladas no Theatro Municipal.

O AIPD marcou, em quase todo o mundo, um período de fortalecimento do debate a respeito da inserção das pessoas com deficiência na sociedade. Quando a ONU foi agenciada para a causa das pessoas com deficiência, a omissão do poder público a respeito do assunto perdeu "força". Paralelamente, diversas entidades se organizaram para chamar atenção da imprensa e promover debates visando melhoras nas condições de vida. Em 1981, o debate sobre acessibilidade entrou "com força" na esfera pública.

Sem dúvidas, a ONU foi uma aliada de peso para a causa das pessoas com deficiência. Aqui, retomamos a questão que abrimos nosso artigo: por que as pessoas com deficiência precisaram brigar por seus direitos? Quais razões para sua exclusão social? Utilizando o referencial teórico dos STS studies, buscaremos esboçar uma resposta para essa questão. Acreditamos que a exclusão se deu pela inconformidade dessas pessoas ao padrão de ser no mundo que foi socialmente estabelecido. 


\subsection{Padrões e traduções: compondo redes sociotécnicas}

Essa seção é baseada no referencial teórico dos STS studies. Como no Brasil os estudos da deficiência foram pouco explorados por essa abordagem, a temática discutida aqui se afastará do tema da deficiência para, na seção seguinte, se aproximar novamente e dar coesão a ideia defendida pelo artigo.

Nesta abordagem, humanos e não-humanos se interconectam, se agenciam, formando ligações que compõem uma rede. De acordo com Bruno Latour (2019), essas redes devem ser compreendidas como a fiação de uma rede elétrica por onde as práticas sociais, os valores morais, a cultura etc. circulam. Mais do que simplesmente evidenciar as conexões que unem humanos e não-humanos, o conceito de rede ajuda a compreender que nosso modo de existência só é possível a partir de determinados elementos que estão interconectados.

Em uma sociedade, coexistem diferentes redes que se conectam, interagem umas com as outras e se transformam. De fato, a própria sociedade, em uma abordagem STS, pode ser encarada como uma grande rede mais ou menos estabilizada. Conforme afirmamos anteriormente, autores como o Bruno Latour, preferem utilizar termos como "coletivo" ou mesmo "modo de existência" para designar esse conjunto de redes que compõe uma sociedade. Nesse sentido, podemos afirmar que as maneiras de ser no mundo são sempre suportadas por redes sociotécnicas que permitem o seu desenvolvimento e sua permanência.

A exclusão social começa quando observamos que esse modo de ser no mundo, um modo padronizado, depende de determinadas associações, deixando de fora, consequentemente, os indivíduos que não possuem determinados atributos tidos como essencial para esse modo de existência.

Existem diversos exemplos cotidianos que suportam esta afirmação: colchões possuem o mesmo tamanho; as camas são feitas para estarem a determinada altura do chão; roupas possuem seus tamanhos proporcionais aos corpos da maior parte da população.

Assim, considerando que a existência tal qual se constituiu é suportada por uma determinada rede sociotécnica e essa mesma existência é baseada em padronizações que desconsideram as especificidades de determinados indivíduos, como compreender o impacto dessas redes nas vidas das pessoas? Em um artigo, Susan Star (1990) parte de sua alergia a cebolas para compreender essa questão. Essa característica do seu organismo, pouca conhecida da maioria da população, gera para a autora toda sorte de desconfortos intestinais sempre que ela come cebolas.

Quando comia em restaurantes, Star se via obrigada a solicitar que seus pratos não levassem cebolas. A menor quantidade delas já era suficiente para lhe fazer mal. Quando a comida lhe era preparada na hora, a autora não vivenciava grandes problemas, no máximo precisava raspar um pedaço ou outro de cebola que aparecia em seu prato. Contudo, em algumas visitas à rede de fast food McDonald's, caracterizada por servir lanches rapidamente, seus pedidos sempre demoravam para serem preparados e entregues. Em uma determinada ocasião, a autora afirmou que, comendo com amigos, todos foram servidor e concluíram suas refeições antes mesmo que seu lanche fosse entregue.

Do ocorrido, Star percebeu que a rede de fast food simplesmente não sabia lidar com sua alergia porque os lanches, padronizados, não foram pensados para indivíduos com essa especificidade. Em outras palavras, a alergia a cebolas fora deixada de lado na rede sociotécnica onde circula as práticas do McDonald's. A autora conclui que fazer parte de uma determinada rede traz uma série 
de benefícios, como por exemplo, adquirir lanches rapidamente em qualquer loja da franquia McDonald's. Porém, para aqueles que não podem participar de determinadas conexões de uma rede, o acesso a recursos disponíveis aos demais cidadãos é ou dificultado ou simplesmente impedido.

Propomos chamar de estandardização a força que uma determinada rede exerce sobre os indivíduos para adequá-los a um modo de existência, uma forma de ser no mundo. Essa adequação pode ser a exclusão de alguns espaços ou a determinação de que alguns indivíduos ocupem espaços que não necessariamente gostariam de ocupar. Historicamente, aqueles que escapam parcialmente deste processo de estandardização tendem a se organizar e reivindicar mudanças que os permitam partilhar de maneira menos violenta de um modo de existência. Muitas vezes, o papel que foi socialmente determinado para um grupo é rejeitado por ele, forçando a rede a se transformar. O movimento negro, feminista, LGBTQIA+ etc. são exemplos de tentativas para a adequação de práticas e valores consolidados buscando assim estender os benefícios de se partilhar uma rede sociotécnica a mais indivíduos. Em alguns casos, esses benefícios são simplesmente o acesso a direitos humanos básicos como o da livre circulação.

Nas ciências sociais, as estruturas discriminatórias da sociedade recebem diversos nomes: racismo, sexismo, Igbtfobia etc. Na mesma linha, teóricos do modelo social da deficiência cunharam o neologismo (ainda sem tradução) disabilism para designar o preconceito que emerge de uma cultura que normalizou os impedimentos corporais (Diniz et al., 2009).

Normalizar uma característica é o primeiro passo para a estandardização, uma vez que a normalização é oriunda da aceitação acrítica da ideia de que existe um padrão de ser e existir no mundo que é mais aceitável em detrimento aos demais. Para Diniz et al., essa normalidade é "entendida ora como uma expectativa biomédica de padrão de funcionamento da espécie, ora como um preceito moral de produtividade e adequação às normas sociais" (Diniz et al., 2009, p. 65). Partindo do pressuposto que é normal ter o corpo funcionando de uma determinada maneira e também é normal ser produtivo, a vida em sociedade foi estandardizada levando-se em conta as necessidades daqueles que estão de acordo com estas características. Quando normalizamos essas ideias aceitamos que existe uma certa homogeneidade de existência e que as diferenças, por serem pontuais, não precisam ser consideradas em âmbito coletivo. No caso das pessoas com deficiência, essa é uma das bases do modelo biomédico, que busca mitigar as "dificuldades" ou mesmo "curar" os indivíduos que desviaram da homogeneidade social. A ideia subjacente é tornar todos o mais parecido, o mais homogêneo possível.

Algumas vertentes sociológicas, contudo, rejeitam frontalmente a ideia de existência de uma homogeneidade social. O sociólogo Gabriel Tarde, por exemplo, afirma que existe uma "tendência inata" da diferenciação dos seres vivos (Marras, 2007). Nesse sentido,

Ordem, harmonia, consenso e estabilidade não passariam de momentos intermediários, intervalos da diferença de onde tudo vem e para onde tudo vai, origem e termo das coisas. Ora, sempre prenhe de heterogeneidades, o dado tende à instabilidade, ao passo que a ordem, a harmonia ou a estabilização resultam de um esforço convencional de construção (Marras, 2007, p. 226).

Para Gabriel Tarde, existir é divergir e o "padrão" é a diferença. Essa é a terceira característica que gostaríamos de ressaltar a respeito das potencialidades das intersecções entre estudos da deficiência e STS studies. Compreender que o padrão é a diferença significa aceitar que manter uma rede sociotécnica estandardizada requer esforço, tendo em vista que a tendência natural é justamente a diferenciação. Michel Callon (1990) afirma que toda rede é temporária e instável, 
sendo necessário agenciar muitos humanos e não-humanos para mantê-la estabilizada. É neste ponto que o conceito de tradução é relevante.

Se o padrão é a diferença, como manter uma rede unida? Uma das respostas possibilitadas por uma abordagem STS é: alinhando interesses. Humanos e não-humanos, por serem diferentes, possuem interesses diferentes. Para uma conexão entre atores ser durável, esses interesses precisam ser traduzidos.

Essa ideia é discutida no livro A Esperança de Pandora, de Bruno Latour (2001). Na obra, o autor apresenta o caso de Frédéric Joliot-Curie, um físico e químico francês que teorizou sobre a possibilidade de realizar uma reação nuclear em cadeia e que tentou produzi-la em seu laboratório na França dos anos 1930. A partir dessa ideia, Joliot e todos aqueles que leram seu artigo publicado a respeito dessa teoria, sabiam da existência da possibilidade de se criar um reator nuclear para produzir energia elétrica. Ou uma bomba. Em resumo, para conseguir conduzir suas pesquisas, Joliot precisaria alinhar sua teoria com as observações de Hans von Halban sobre a desaceleração de nêutrons em uma “água pesada" rara e produzida exclusivamente por uma empresa norueguesa. Joliot precisaria também conseguir altos investimentos, que foram concedidos por uma mineradora chamada Union Minière, que possuía grande quantidade de refugos radioativos que era inútil para a companhia até a proposta de criação de um reator feita por Joliot. Além da mineradora, Joliot conseguiu investimentos realizados pelo Estado francês com a condição de inverter a prioridade de sua pesquisa: caso fosse viável, Joliot deveria produzir primeiro a bomba. O que Latour demonstra ao longo do capítulo dedicado a esse caso, é que os interesses da Union Minière se traduziram nos de Joliot, que, por sua vez, também foram traduzidos no desejo do Estado francês em conseguir uma bomba, e assim por diante (Latour, 2001, pp. 97-132). Diversas traduções foram realizadas no entorno de Joliot para que seu objetivo fosse concretizado.

Na introdução, apontamos o caráter difundido da tradução. Além dos interesses, podemos explorar traduções no âmbito das coisas, como observado em Bernardino Junior (2020). O estudo é feito através da análise dos circuitos microeletrônicos desenvolvidos pelo Laboratório de Sistemas Integráveis da Escola Politécnica da Universidade de São Paulo. Uma das pesquisas realizadas pelo professor João Antônio Zuffo, encarregado deste Laboratório, buscava armazenar em memória digital dados numéricos em formato decimal. Usualmente, aparelhos eletrônicos trabalham com números binários, ou seja, apenas os algarismos o e 1. Tal característica tornaria a utilização de dados decimais um contrassenso, caso o interesse fosse a construção de uma máquina barata e comercialmente viável. Contudo, Zuffo estava interessado em pesquisa de base e no desenvolvimento de uma tecnologia própria, justificando tal empreendimento.

Como não existia necessidade de construção das memórias que armazenariam a informação, uma vez que as mesmas poderiam ser adquiridas no mercado, Zuffo construiu um circuito que permitia que números decimais fossem armazenados em uma memória binária. A adição dessa tradução permitiu que o interesse pelo desenvolvimento de uma tecnologia própria dialogasse com um padrão tecnológico consolidado internacionalmente.

Assim, observamos que são as traduções que permitem convergências em redes sociotécnicas. É essa prática que dá “coesão” a sociedade, conforme os exemplos apresentados anteriormente.

No artigo Technology is Society Made Durable (Latour, 1990), Bruno Latour afirma que as traduções propiciadas pelas tecnologias são o que torna a sociedade durável. Sem o tipo de coesão e o tipo de controle propiciados pelas técnicas, a sociedade se desmantelaria, pois não haveria convergências suficientes de interesse. Possibilitar a extensão dos benefícios sociais para outros grupos de humanos (e não-humanos) através das traduções também torna a sociedade mais 
durável na medida em que estabilizam as relações que poderiam perturbar o tecido social. Como diria Gabriel Tarde, as coisas precisam mudar para continuarem como são (Marras, 2007).

Com base no exposto, buscaremos compreender, na última seção, como os estudos da deficiência e os STS studies podem se interconectar através dos três pontos que ressaltamos até aqui: 1. social e biológico fazem parte do mesmo todo; 2. traduções são práticas que dão coesão à sociedade; 3. o padrão é a diferença.

\subsection{Acessibilidade como forma de tradução}

A acessibilidade é retratada, nos estudos sobre deficiência, como recursos materiais, atitudinais, comunicacionais etc. que permite às pessoas com deficiência gozarem com mais autonomia e segurança dos benefícios sociais disponíveis. A Lei Brasileira da Inclusão define a acessibilidade como:

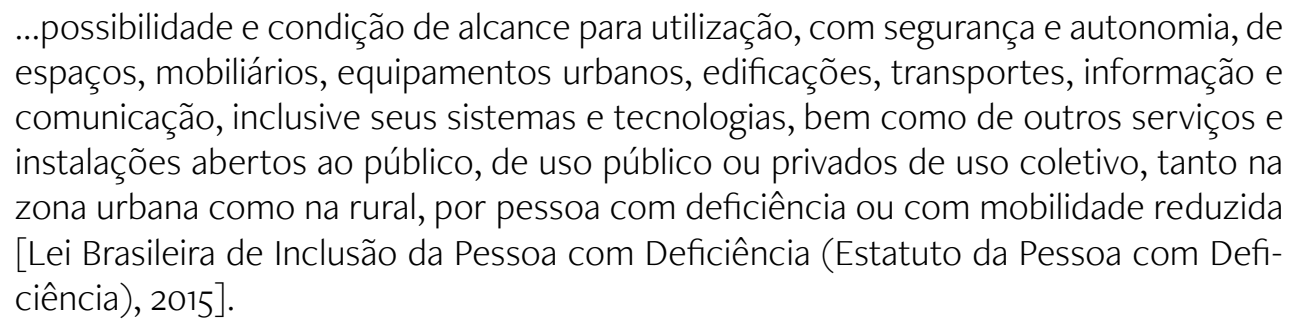

Um exemplo prático da aplicação deste conceito é a existência de rampas em espaços que possuem escadas. A escada, uma barreira arquitetônica, dificulta a locomoção de pessoas em cadeira de rodas, bem como daqueles que utilizam muletas, andadores, são obesos, grávidas etc. A colocação de rampas em espaços com escadas é uma medida que visa fornecer acessibilidade ao espaço.

Dando um passo atrás na necessidade de implementação de recursos acessíveis, podemos refletir acerca da necessidade de existência da própria escada. A razão de existir de uma escada é conduzir indivíduos a um espaço maior que o tamanho de suas pernas permitiria. A escada em si é uma tradução, pois apresenta-se como um diálogo entre o corpo e o ambiente. Ela não é, contudo, a única maneira de aplicar uma tradução. Podemos imaginar um cenário absurdo onde a escada seja substituída por uma corda, por exemplo. É absurdo porque o condicionamento físico necessário para se subir por uma corda de um andar para outro é tamanho que, na prática, excluiria uma parcela considerável da população. A princípio, podemos considerar a escada uma tradução mais democrática que uma corda, porém ainda assim excludente.

Então, por que a mobilização de um movimento social foi necessária para conferir a tradução "chegar a um espaço elevado" uma formulação ainda mais abrangente? Em outras palavras, porque é aceitável excluir um grupo (o das pessoas com deficiência) e não outro (as pessoas sem condicionamento físico para subir cordas)? Será unicamente por uma questão quantitativa (existem menos pessoas com deficiência do que existem pessoas sem condicionamento)?

Através de estudos que pensam a respeito das desigualdades, compreendemos que o indivíduo estandardizado é aquele que é produtivo, branco, cis e todos aqueles estereótipos reforçados constantemente através de veículos de comunicação em massa. Esse padrão por si exclui a maioria das pessoas, principalmente em países que pertencem ao que Boaventura dos Santos chama de sul global (Santos, 2007). 
Se reformularmos nossa questão inicial a partir dessa ótica, podemos obter a seguinte sentença: compreendemos que o social e o biológico fazem parte do todo e que a variedade de possibilidades torna a diferença o padrão, obrigando, portanto, que traduções existam para possibilitar a existência coletiva. Por que, então, pessoas com deficiência precisaram lutar para garantir uma existência que é naturalmente garantida para os indivíduos estandardizados?

A nosso ver, compreender que traduções são sempre necessárias e que aquelas que foram socialmente escolhidas deliberadamente exclui pessoas com deficiência unicamente porque elas não se encaixam no ideal de indivíduo estandardizado torna a falta de acessibilidade ainda mais escandalosa. A inacessibilidade não existe por falta de recursos ou falta de empatia a respeito de como se comunicar ou como tratar uma pessoa com deficiência, a inacessibilidade existe porque, socialmente, escolhemos segregar esse grupo por acreditarmos que, por serem diferentes, não precisam compartilhar os espaços públicos com os demais.

Apesar de pequenos avanços na área de acessibilidade inclusão ocorrerem no Brasil desde o final dos anos 1970 por conta do Movimento Social das Pessoas com deficiência, foi apenas em 2009, através do decreto n 6.949 de 2009, que promulgou a Convenção Internacional sobre os Direitos das Pessoas com Deficiência, que o país vivenciou avanços mais significativos na área.

A partir dessa nova legislação, ficou assegurada, pelo menos na lei, que os espaços coletivos abranjam diferentes formas de ser no mundo. A legislação é tão completa que garante que novos espaços sejam inteiramente planejados de maneira acessível, respeito assim a chamada “acessibilidade plena". Nesse conceito, as traduções precisam necessariamente serem pensadas de maneira mais democrática e abrangente. Para os espaços já existentes, construídos de maneira inacessível, a lei prevê a chamada "adaptação razoável”, definida como:

...as modificações e os ajustes necessários e adequados que não acarretem ônus desproporcional ou indevido, quando requeridos em cada caso, a fim de assegurar que as pessoas com deficiência possam gozar ou exercer, em igualdade de oportunidades com as demais pessoas, todos os direitos humanos e liberdades fundamentais (Decreto $n^{\circ} 6.949$ de 25 de agosto de 2009, 2009).

É interessante notar que, no caso da legislação brasileira para acessibilidade, o acréscimo de traduções que resultam em adaptações razoáveis é um estágio "provisório", ou seja, apenas para os casos em que não se pode proporcionar uma acessibilidade plena.

Enquanto a adaptação razoável busca construir traduções em uma rede já estabilizada, a acessibilidade plena busca a construção de novas redes sociotécnicas com diferentes agências capazes de atender a um número maior de humanos desde o momento de sua construção. É um novo tipo de estandardização, mais flexível e que carrega a ideia de que a diferença (e não a igualdade) é a regra.

\section{CONCLUSÃO}

As áreas de estudos da deficiência e das ciências, tecnologias e sociedade possuem intersecções que possibilitam compreender a questão da acessibilidade através de uma ótica diferente. Uma sociedade acessível é, tradicionalmente, concebida como uma sociedade que recebe "acréscimos", traduções que permitiram que indivíduos com ou sem deficiência que estavam de fora da rede estandardizada passassem a fruir com autonomia e segurança dos benefícios da vida coletiva.

Quando relacionamos acessibilidade com tradução, relativizamos a ideia de acréscimo e enxergamos a inacessibilidade como uma escolha. Traduções serão sempre necessárias para a vida 
social e, portanto, a acessibilidade não deve ser encarada como um novo elemento acrescentado ao que já existe e sim como a escolha de elementos que por si só já permitem agências com uma variedade maior de indivíduos.

Através da sociologia de Gabriel Tarde, salientamos que o padrão é a diferença e que, portanto, a construção de uma sociedade baseada nas necessidades de indivíduos historicamente estandardizados eventualmente não atende aos interesses da maioria da população. Através da escolha de traduções democráticas e mais adequada ao padrão real, que é a diversidade, é possível construir uma sociedade mais igualitária e inclusiva sem a necessidade de acréscimos que resultam apenas de adaptações razoáveis.

\section{REFERÊNCIAS}

Bernardino Junior, C. (2020). Dois arranjos em prol do desenvolvimento tecnológico na Escola Politécnica da USP: FINEP-LSI e FTDE-LSD (1974-1985) [Mestrado em História Social, Universidade de São Paulo]. https://doi.org/10.11606/D.8.2020.tde-21022020-141757

Callon, M. (1990). Techno-economic Networks and Irreversibility. The Sociological Review, 38(1), 132-161. https://doi.org/10.1111/j.1467-954X.1990.tbo3351.x

Decreto $n^{0}$ 85.123, de 10 de Setembro de 1980, (1980) (testimony of Presidência da República). https:// www2.camara.leg.br/legin/fed/decret/1980-1987/decreto-85123-10-setembro-1980-434479publicacaooriginal-1-pe.html

Decreto $n^{\circ} 6.949$ de 25 de agosto de 2009, (2009) (testimony of Presidência da República). http://www. planalto.gov.br/ccivil_03/_at02007-2010/2009/decreto/d6949.htm

Diniz, D. (2012). O que é deficiência ( $1^{\circ}$ ed). Editora Brasiliense.

Diniz, D., Barbosa, L., \& Santos, W. R. dos. (2009). Deficiência, direitos humanos e justiça. Sur. Revista Internacional de Direitos Humanos, 6(11), 64-77. https://doi.org/10.1590/S1806-64452009000200004

Editorial (30 de abril de 1974). Deficiente auditivo não tem assistência. Folha de São Paulo, p. 10.

Editorial ( 5 de abril de 1979). Os ambulantes estão contra novas bancas. Folha de São Paulo, p. 19.

Editorial (13 de março de 1981). Deficientes divulgarão programa para este ano. Folha de São Paulo, p. 11.

Editorial (19 de março de 1980). Cadeira de rodas. (1980, março 19). Folha de São Paulo, p. 31.

Editorial (1 de maio de 1981). Primeira linha de ônibus para os deficientes. Folha de São Paulo, p. 09.

Editorial (9 de maio de 1980). Avenida volta a ser ocupada por ambulantes. Folha de São Paulo, p. o6.

Editorial (11 de maio de 1980). Ajuda para os deficientes físicos. Folha de São Paulo, p. 21.

Editorial (22 de julho de 1980). Problemas dos deficientes físicos debatidos em SP. Folha de São Paulo, p. 11.

Editorial (2 de maio de 1981). Ônibus especial não atende deficientes. Folha de São Paulo, p. 09.

Escola Politécnica de Saúde Joaquim Venâncio. ([s.d.]). Instituto Nacional de Assistência Médica da Previdência Social (INAMPS). |Escola Politécnica de Saúde Joaquim Venâncio. https://cutt.ly/BQd4zDz

Lanna Júnior, M. C. M. (2010). História do Movimento Político das Pessoas com Deficiência no Brasil. Secretaria de Direitos Humanos. Secretaria Nacional de Promoção dos Direitos da Pessoa com Deficiência.

Latour, B. (1990). Technology is Society Made Durable. The Sociological Review, 38(1_suppl), 103-131. https:// doi.org/10.1111/j.1467-954X.1990.tbo3350.x

Latour, B. (2001). A esperança de Pandora: Ensaios sobre a realidade dos estudos científicos. EDUSC.

Latour, B. (2009). Jamais fomos modernos: Ensaio de antropologia simétrica. Editora 34.

Latour, B. (2019). Investigação sobre os modos de existência: Uma antropologia dos modernos. Editora Vozes.

Lei Brasileira de Inclusão da Pessoa com Deficiência (Estatuto da Pessoa com Deficiência), no 13.146 (2015).

Marras, S. (2007). Tarde reconquistado. Novos Estudos-CEBRAP, 78, 221-231. https://doi.org/10.1590/So10133002007000200018 
Santos, B. de S. (2007). Para além do pensamento abissal: Das linhas globais a uma ecologia de saberes. Novos Estudos-CEBRAP, 79, 71-94. https://doi.org/10.1590/S0101-33002007000300004

Silva, V. L. M. P. da. (2017). Um olhar sobre a FCD: seu caminhar em direção à inclusão das pessoas com deficiência (Tese Doutorado). Universidade Metodista de São Paulo.

Star, S. L. (1990). Power, Technology and the Phenomenology of Conventions: On being Allergic to Onions. The Sociological Review, 38(1), 26-56. https://doi.org/10.1111/j.1467-954X.1990.tb03347.x

\section{AUTORES}

Carla Grião. Mestranda em Culturas e Identidades Brasileiras pelo Instituto de Estudos Brasileiros da Universidade de São Paulo. Bacharela em Museologia pela Universidade Federal de Ouro Preto (UFOP). Cláudio Bernardino Junior. Mestre em História Social pela Faculdade de Filosofia, Letras e Ciências Humanas da Universidade de São Paulo. Bacharel e licenciado em História pela mesma instituição. Possui pesquisas publicadas na área de História das Ciências e das Tecnologias. Atualmente, é docente da educação básica na Rede de Ensino da Prefeitura Municipal de São Paulo.

\section{Conflicto de intereses}

El autor(es) informa(n) ningún conflicto de interés posible.

\section{Financiamiento}

No existió asistencia financiera de partes externas al presente artículo.

\section{Agradecimientos}

$$
\mathrm{N} / \mathrm{A}
$$

\section{Nota}

O presente artigo é derivado das pesquisas de mestrado de Carla Grião e de Cláudio Bernardino Junior. O objeto de estudos primário (a acessibilidade e os estudos do Movimento Social das Pessoas com Deficiência) advém da pesquisa de Grião, enquanto a fundamentação teória das traduções possui elementos utilizados na pesquisa de Bernardino Junior. 